\title{
Tooth whitening recovers the color of pre-stained composites
}

\author{
Camila Bruscato Farinon ${ }^{1}$, Giovanna Signori Pasqualotto ${ }^{1}$, Kauani Carraro' ${ }^{1}$, Sinval Adalberto Rodrigues-Junior ${ }^{1}$ \\ 'Universidade Comunitária da Região de Chapecó - Unochapecó, School of Dentistry, Health Sciences Area, Chapecó, SC, Brazil
}

Received for publication: July 20, 2016 Accepted: November 16, 2016

Correspondence to: Sinval Adalberto Rodrigues-Junior Universidade Comunitária da Região de Chapecó Área de Ciências da Saúde - Caixa Postal 1141 Av. Senador Atílio Fontana, n. 591-E - Efapi CEP 89809-000 - Chapecó - SC - Brasil Phone: +55 49 3321-8069

E-mail: rodriguesjunior.sa@unochapeco.edu.br

\begin{abstract}
Aim: To assess the effect of home-whitening on aged and stained composite. Methods: Fifteen discshaped specimens (10 mm diameter $\times 2 \mathrm{~mm}$ thick) of Filtek Z350XT, shade A2E were fabricated, polished and embedded in wax, leaving exposed the top surface. The specimens were allocated to three groups $(n=5)$ : A - the specimens remained dry; $B$ - conditioning in distilled water and; C - conditioning in distilled water and coffee. They were next subjected to whitening with $10 \%$ carbamide peroxide (Whiteness Perfect) for $4 \mathrm{~h}$ daily for 1,2 and 4 weeks. Shade was measured with a spectrophotometer Easyshade and expressed based on the $C\left(E L^{*} a^{*} b^{*}\right.$ system $\left(\Delta E^{*}\right)$. Surface roughness was measured with a roughness meter (Ra- $\mu \mathrm{m})$. Data were analyzed with two-way ANOVA and Tukey's test $(\alpha=0.05)$. Results: Conditioning, grouping and the interaction between both, influenced the $\Delta \mathrm{E}^{*}(\mathrm{p}<0.0001)$, which exceeded the 3.3 threshold for visible color change after conditioning of Group $C$ in black coffee. Whitening for 1 week significantly reduced $\Delta \mathrm{E}^{*}$ in this group. There were no significant changes in surface roughness. Conclusions: Home-whitening did not alter significantly the color of the nanocomposite, except when it was previously stained. One-week whitening was sufficient to recover color change to an acceptable level.
\end{abstract}

Keywords: Tooth Bleaching. Tooth Bleaching Agents. Dental Restoration, Permanent.

\section{Introduction}

Tooth whitening has become a major elective demand for dentists in restorative dentistry nowadays ${ }^{1}$. Usually, the protocol involves advising patients that restored anterior teeth to be whitened would probably have the restoration replaced after tooth whitening, due to discrepancies of color between the recently whitened tooth structure and the restoration ${ }^{2,3}$. However, it is not uncommon the report of dentists that replacing the restoration was not necessary due to color match with the bleached tooth. Based on this observation, it is hypothesized that the resin composite also undergoes color change during tooth whitening.

Color change in resin composites is well known, either due to intrinsic or extrinsic factors $^{4,5}$. Intrinsic factors involve the hydrolytic degradation and release of constituents, while extrinsic factors involve the incorporation of pigments by staining substances from the diet ${ }^{4}$. Hydrolytic degradation is inherent to dimethacrylate-based composites in contact with a wet environment, leading ultimately to a more porous restoration ${ }^{6}$. Although the increase of porosity of the restoration makes it more prone to staining, water diffusion alone revealed being insufficient to lead to significant, visible color change of a composite restoration ${ }^{4}$.

Color change in Dentistry has been expressed quantitatively, based on the CIE $\mathrm{L}^{*} \mathrm{a} * \mathrm{~b}^{*}$ system. This system provides a summarizing measure $\left(\Delta \mathrm{E}^{*}\right)$ that represents 
the overall color change, and may be classified into three distinct intervals, considering the ability of the human eye to recognize differences in colors: a $\Delta \mathrm{E}^{*}<1$ is considered imperceptible by the eye, while $1<\Delta \mathrm{E}^{*}<3.3$ is considered visible only to a skilled person and $\Delta \mathrm{E}^{*}>3.3$ is easily detected by anyone, characterizing the color change of a restoration as clinically unacceptable ${ }^{7,8}$. Other studies have confirmed the color changing effect of several extrinsic pigments from dietary sources, including grape juice, red wine and coffee ${ }^{4,8-10}$.

Considering the capillarity of the restorative composite to staining molecules, it seems fair to assume that the hydrogen peroxide $\left(\mathrm{H}_{2} \mathrm{O}_{2}\right)$ resulting from the tooth whiteners would also percolate the material's structure, due to its low molecular weight ${ }^{1}$. Prior studies have shown some evidence of dental composites whitening ${ }^{3,9}$, but, the extent to which it is whitened and whether this is sufficient to maintain the restoration following tooth whitening still remains uncertain ${ }^{3}$. On that basis, this study was designed to verify whether tooth whitening alters the color of a universal nanocomposite and to test the hypothesis that significant color alteration after whitening only occurs when the composite contains acquired extrinsic pigments.

\section{Material and methods}

Fifteen disc-shaped specimens with $10 \mathrm{~mm}$ diameter and 2 $\mathrm{mm}$ thick were built up in a single increment with the universal composite Filtek Z350XT (3M/ESPE, St. Paul, MN, USA), shade A2E. The sample size was calculated by G*Power 3.1.9.2 (Universität Düsseldorf, Düsseldorf, Germany) considering a type I error probability of 0.05 , a test power of $95 \%$, one tail and a 3.3 effect size, based on the clinically visible $\Delta \mathrm{E}^{* 7}$. The specimens were light cured for $20 \mathrm{~s}$ using an Ultraled lightcuring unit (Dabi Atlante, Joinville, SC, Brazil) with a minimum irradiance of $600 \mathrm{~mW} / \mathrm{cm}^{2}$. Next, the specimens were polished with Diamond Pro (FGM, Joinville, SC, Brazil) sequential discs of decreasing particle sizes at low speed and embedded in white wax, except for the irradiated/polished surface.

The specimens were randomly allocated to three groups $(\mathrm{n}=5)$, according to Figure 1 .

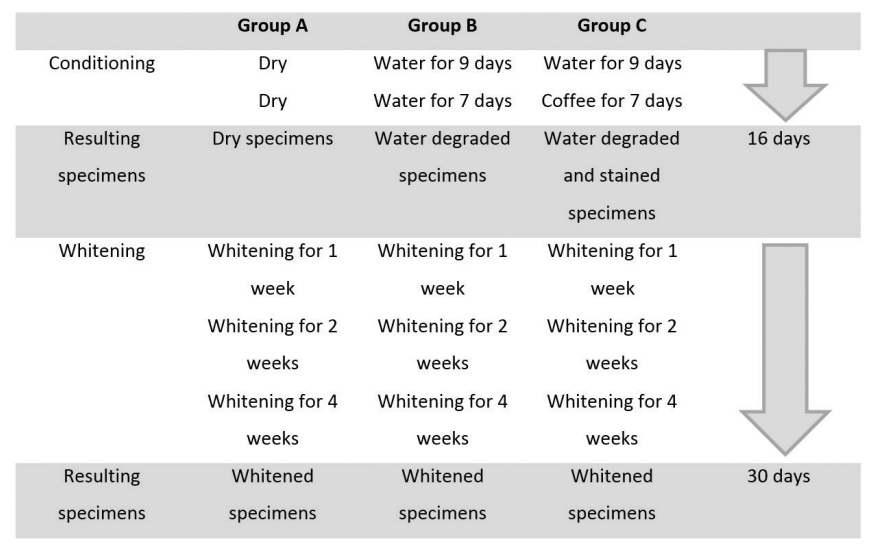

Fig.1. Study flow diagram involving conditioning and whitening procedures and times.
Group A: a total 16-day conditioning period prior to whitening involved water degradation and staining of the specimens. Specimens of Group A remained dry during this conditioning period for control purposes.

Group B: the specimens were stored for 9 days in distilled water as a means of imposing hydrolytic degradation. The ageing period was previously determined as required for total water sorption and solubilization of components of a 2-mm thick specimen11. The specimens were kept in distilled water during the next 7-day period.

Group C: these specimens were conditioned for 9 days in distilled water, similar to Group B and then for 7 days in black coffee.

After this, dry, degraded and pigmented specimens were submitted to whitening. Conditioning occurred at $37^{\circ} \mathrm{C}$. Following the 16-day conditioning period, the specimens of the three groups were submitted to whitening with $10 \%$ carbamide peroxide gel (Whiteness Perfect, FGM) for $4 \mathrm{~h}$ daily during 1, 2 and 4 weeks.

Between each conditioning and whitening period the specimen's shade was measured with a spectrophotometer Easyshade (Vita Zahnfabrik, Bad Säckingen, Germany) and expressed based on the CIE L*a*b* system. Color was measured with the spectrophotometer's tip in contact and perpendicular to the specimen's surface. A standard white background was used for all measurements.

The CIE L*a*b* is a three-dimensional color space. L* stands for lightness and varies from 0 (black) to 100 (white). $a^{*}$ varies between green (negative $a^{*}$ ) and red (positive $a^{*}$ ) and $b^{*}$ varies between blue (negative $b^{*}$ ) and yellow (positive $\left.b^{*}\right)$. Variations between measures throughout different periods generate the deltas $\left(\Delta \mathrm{L}^{*}, \Delta \mathrm{a}^{*}\right.$ and $\left.\Delta \mathrm{b}^{*}\right)$ that, ultimately, yield the $\Delta \mathrm{E}^{*}$, which represents the overall color change by the following equation.

$$
\Delta \mathrm{E}_{\mathrm{ab}}^{*}=\sqrt{\left(L_{2}^{*}-L_{1}^{*}\right)^{2}+\left(a_{2}^{*}-a_{1}^{*}\right)^{2}+\left(b_{2}^{*}-b_{1}^{*}\right)^{2}}
$$

Additionally, the surface roughness was measured with a RP-200 roughness meter (Instrutherm, São Paulo, SP, Brazil), by three parallel readings along $4 \mathrm{~mm}$ length with a cut-off setting of $0.8 \mathrm{~mm}$.

Data were analyzed with two-way analysis of variance and post-hoc Tukey test $(\alpha=0.05)$.

\section{Results}

Variance analysis depicted significant differences in $\Delta \mathrm{E}^{*}$ due to conditioning $(\mathrm{p}<0.0001)$, to grouping $(\mathrm{p}<0.0001)$ and to the interaction between both $(\mathrm{p}<0.0001)$. Color change was highly significant following conditioning of Group $\mathrm{C}$ in black coffee, exceeding the 3.3 threshold for visible color change. Such color change returned to acceptable levels after whitening for 1 week and kept decreasing during the two-week and four-week whitening (Table 1 and Figure 1). This reflected the significant decrease of $\mathrm{L}^{*}$ (darkening) and increase of $\mathrm{b}^{*}$ 
(yellowing) following storage of specimens of Group $\mathrm{C}$ in black coffee (Figure 1-A and C). Recovery of lightness was observed following one-week whitening, while significant reduction of yellowing occurred only after four-week whitening.

Table 1 - Results of $\mathrm{L}^{*}, \mathrm{a}^{*}, \mathrm{~b}^{*}, \Delta \mathrm{E}^{*}$ and average surface roughness $(\mathrm{Ra}-\mu \mathrm{m})($ mean and SD) after conditioning and whitening.

\begin{tabular}{|c|c|c|c|c|}
\hline \multirow[b]{2}{*}{ Conditioning } & & \multicolumn{3}{|c|}{ Groups } \\
\hline & & Group A & Group B & Group C \\
\hline \multirow[t]{4}{*}{ Baseline } & $\mathrm{L}^{*}$ & $79.3(1.6)^{A}$ & $79.0(0.5)^{\mathrm{A}}$ & $78.9(0.9)^{A}$ \\
\hline & $a^{*}$ & $0.3(0.2)$ & $0.1(0.3)$ & $-0.1(0.2)$ \\
\hline & $b^{*}$ & $19.9(1.3)^{\mathrm{B}}$ & $19.4(0.3) \mathrm{B}$ & $19.0(0.8)^{\mathrm{B}}$ \\
\hline & $\mathrm{Ra}$ & $0.204(0.064)$ & $0.298(0.164)$ & $0.244(0.102)$ \\
\hline \multirow[t]{5}{*}{ Conditioning step $1 \dagger$} & $L^{*}$ & $78.8(1.8)^{\mathrm{A}}$ & $79.7(0.7)^{\mathrm{A}}$ & $79.8(0.8)^{\mathrm{A}}$ \\
\hline & $a^{*}$ & $-0.1(0.2)$ & $0.5(0.3)$ & $0.2(0.2)$ \\
\hline & $b^{*}$ & $18.9(1.3)^{\mathrm{B}}$ & $20.2(0.4)^{\mathrm{B}}$ & $19.7(0.9)^{\mathrm{B}}$ \\
\hline & $\Delta \mathrm{E}^{*}$ & $1.2(0.5)^{\mathrm{BCD}}$ & $1.2(0.3)^{B C D}$ & $1.2(0.5)^{\mathrm{BCD}}$ \\
\hline & $\mathrm{Ra}$ & $0.214(0.075)$ & $0.301(0.149)$ & $0.236(0.090)$ \\
\hline \multirow[t]{5}{*}{ Conditioning step $2 \ddagger$} & $\mathrm{L}^{*}$ & $78.9(2.0)^{A}$ & $78.7(0.6)^{A B}$ & $76.1(1.3)^{c}$ \\
\hline & $a^{*}$ & $0.1(0.4)$ & $0.7(0.2)$ & $0.6(0.6)$ \\
\hline & $b^{*}$ & $19.8(1.6)^{\mathrm{B}}$ & $19.4(0.5)^{\mathrm{B}}$ & $24.6(2.0)^{\mathrm{A}}$ \\
\hline & $\Delta \mathrm{E}^{*}$ & $1.1(0.6)^{C D}$ & $0.7(0.2)^{\mathrm{D}}$ & $6.3(2.2)^{A}$ \\
\hline & $\mathrm{Ra}$ & $0.198(0.068)$ & $0.220(0.047)$ & $0.261(0.109)$ \\
\hline \multirow[t]{5}{*}{ Whitening 1 week } & $L^{*}$ & $78.2(1.6)^{A B}$ & $78.2(1.2)^{A B}$ & $77.7(0.9)^{\mathrm{AB}}$ \\
\hline & $a^{*}$ & $0.6(0.2)$ & $1.2(0.2)$ & $0.8(0.4)$ \\
\hline & $b^{*}$ & $19.5(1.5)^{\mathrm{B}}$ & $19.5(0.4)^{\mathrm{B}}$ & $21.3(1.2)^{\mathrm{AB}}$ \\
\hline & $\Delta \mathrm{E}^{*}$ & $1.3(0.4)^{\mathrm{BCD}}$ & $1.4(0.3)^{\mathrm{BCD}}$ & $2.8(0.9)^{\mathrm{B}}$ \\
\hline & $\mathrm{Ra}$ & $0.218(0.069)$ & $0.222(0.050)$ & $0.235(0.074)$ \\
\hline \multirow[t]{5}{*}{ Whitening 2 weeks } & $\mathrm{L}^{*}$ & $78.7(1.5)^{\mathrm{AB}}$ & $78.4(0.3)^{A B}$ & $78.6(0.7)^{\mathrm{AB}}$ \\
\hline & $a^{*}$ & $1.2(0.4)$ & $1.3(0.3)$ & $1.0(0.3)$ \\
\hline & $b^{*}$ & $19.9(1.6)^{\mathrm{B}}$ & $19.6(0.3)^{\mathrm{B}}$ & $21.1(1.0)^{\mathrm{AB}}$ \\
\hline & $\Delta \mathrm{E}^{*}$ & $1.3(0.4)^{\mathrm{BCD}}$ & $1.4(0.2)^{B C D}$ & $2.5(0.6)^{\mathrm{BC}}$ \\
\hline & $\mathrm{Ra}$ & $0.195(0.073)$ & $0.222(0.034)$ & $0.254(0.058)$ \\
\hline \multirow[t]{5}{*}{ Whitening 4 weeks } & $\mathrm{L}^{*}$ & $78.4(1.7)^{\mathrm{AB}}$ & $78.8(0.6)^{A}$ & $78.0(0.6)^{\mathrm{AB}}$ \\
\hline & $a^{*}$ & $1.3(0.3)$ & $1.6(0.2)$ & $0.9(0.3)$ \\
\hline & $b^{*}$ & $19.2(1.7)^{\mathrm{B}}$ & $19.2(0.4)^{\mathrm{B}}$ & $20.2(0.5)^{\mathrm{B}}$ \\
\hline & $\Delta \mathrm{E}^{*}$ & $1.7(0.4)^{\mathrm{BCD}}$ & $1.6(0.2)^{B C D}$ & $2.0(0.4)^{\mathrm{BCD}}$ \\
\hline & $\mathrm{Ra}$ & $0.204(0.073)$ & $0.205(0.040)$ & $0.261(0.092)$ \\
\hline
\end{tabular}

$\dagger$ Immersion of specimens of groups $B$ and $C$ in water for degradation means. Specimens of group $A$ were kept dry. $\ddagger$ Immersion of specimens of group $C$ in coffee for staining. Specimens of group A were kept dry and of group B were kept in water. Different letters in the row represent statistically significant difference between groups.

No significant changes in surface roughness were observed with either conditioning or whitening procedures $(\mathrm{p}>0.05)$ (Table 1).

\section{Discussion}

This study was designed to test the hypothesis that whitening of the composites occurs following a degradation period and the incorporation of extrinsic staining molecules. The degradation period of 9 days was based on prior calculation that considered the time for water sorption in a 2-mm thick specimen ${ }^{11}$. According to Ferracane ${ }^{12}$ (2006), clinically placed restorations take up to two months to fully saturate with solvent and leach unconverted components. Other surfaces than the irradiated/polished surface were protected in wax, exposing a single way of percolation through the specimen, similar to what occurs in the clinical situation ${ }^{13}$.

The susceptibility of the composite to percolation of staining substances is related to its chemical composition, which includes the type of monomer, the type of inorganic filler, the used photoinitiator and the quality of the matrix/filler interface ${ }^{14}$. It is also modulated by its degree of conversion and network characteristics, since a low degree of conversion leads to degradation of the polymer network and release of byproducts ${ }^{6,12,15,16}$. The nanocomposite used in this study is recommended to both anterior and posterior restorations and has been characterized elsewhere ${ }^{17}$, revealing a degree of conversion of $46 \%$ on the top surface and of $38 \%$ on the bottom surface of a $2-\mathrm{mm}$ thick specimen. According to the authors, light-scattering effects of the nanoclusters could possibly explain the reduction of degree of conversion in depth in this composite ${ }^{17}$.

Conditioning in distilled water for nine days generated a $\Delta \mathrm{E}^{*}$ of 1.2 for all groups. Interestingly, specimens from Group A, which remained dry during this conditioning period, also had the same color change as the ones stored wet. Also, color change was below the 3.3 threshold and within the interval of detection only by a skilled person, meaning that an insignificant color change to the patient's eyes occurs due to hydrolytic degradation ${ }^{4,9}$.

According to Mendes et al. ${ }^{14}$ (2012), degradation of the composite is a modulating factor for the uptake of extrinsic pigments. Water sorption and swelling affect the total volume of the restoration and its porosity ${ }^{12,15}$, enabling the uptake of staining solutions. Conditioning of the specimens from Group $\mathrm{C}$ in coffee following degradation, significantly affected $\Delta \mathrm{E}^{*}$ as a reflection of yellowing (significant increase of $\mathrm{b}^{*}$ color coordinate) and darkening (significant reduction of $\mathrm{L}^{*}$ color coordinate) (Table 1). Staining would probably be higher if the other surfaces of the specimen were not protected with wax. Even so, an easily perceptible $6.3 \Delta \mathrm{E}^{*}$ was observed in Group $\mathrm{C}$ as a consequence of conditioning in coffee. As to the specimens from Groups A and B, stored dry and wet, respectively, no significant color change was observed.

The staining potential of coffee has been attributed to the presence of yellow colorants ${ }^{4}$, which could be confirmed by the significant alteration in the $b^{*}$ axis. Garoushi et al. ${ }^{18}$ (2013) observed that staining solutions not containing yellow colorants presented a lower staining potential. Bagheri et al. ${ }^{19}$ (2005) noticed that color changes higher than 3.3 are often associated to darkening and yellowing, the $\mathrm{L}^{*}$ component being the most significant for color change. In our study, lightness was recovered with one-week whitening, while yellowing took four weeks to reduce significantly. This may be explained by the whitening mechanism of hydrogen peroxide that breaks dark complex pigment molecules into simpler structures with lighter optical characteristics. Therefore, lightness is more quickly achieved than the recovery of yellowing.

Whitening with $10 \%$ carbamide peroxide for one week significantly reduced color change from 6.3 to 2.8 , and kept reducing it during the subsequent weeks to levels similar to the groups that were not stained (Table 1). The diffusion of $\mathrm{H}_{2} \mathrm{O}_{2}$ across enamel and dentin is a well-recognized phenomenon ${ }^{1,20}$ that occurs based on the Fick's second law of diffusion, considering enamel and dentin as semipermeable membranes and several other variables, such as the surface area, the diffusion coefficient, the concentration and the diffusion distance ${ }^{1}$. Water sorption by composites is also known to respect the same laws of diffusion ${ }^{12}$; nevertheless, little is known 
about the diffusion of $\mathrm{H}_{2} \mathrm{O}_{2}$ into previously degraded composite restorations, an issue that demands further research.

Still, one could observe significant whitening of the stained specimens. The whitening mechanism, as it is understood up to now, involves the release of reactive oxygen and its interaction with high molecular weight organic chromophore molecules breaking them into simpler structures with final optical properties that reduce the appearance of $\operatorname{stain}^{1,9,21}$. This was clearly observed in specimens of Group C. However, the lack of significant color change in the specimens from groups $\mathrm{A}$ and $\mathrm{B}$ reinforces the hypothesis that whitening of composites occurs by removal of extrinsic stain, not to intrinsic color change $e^{9,22}$.

No significant change in surface roughness was observed throughout the treatment conditions, in either group. Expectations were that degradation would lead to solubilization of non-converted monomers, oligomers, catalysts, silane and other by-products, which would expose and dislodge filler particles, increasing surface roughness ${ }^{6,12}$. This would lead to a more porous surface rising the percolation way for either the staining solution or the whitener. However, neither conditioning in water, nor in the staining solution, nor the whitening procedure were sufficient to increase surface roughness, similar to other studies ${ }^{2,14}$.

Prior studies have shown that the effect of whiteners on restorative materials are material-dependent ${ }^{3,9}$, and vary according to the material's composition and microstructure. The constituents of the composite generate a tridimensional microstructure that involves the polymer matrix, the inorganic filler and the matrix/ filler interface ${ }^{17}$. Hydrolytic degradation of the matrix or the matrix/ filler interface generates percolation paths to both staining molecules and whitener. According to Fontes et al. ${ }^{8}$ (2009), the presence of specific monomers, like TEGDMA, make the composite more prone to degradation. Li and Wang ${ }^{3}$ (2009) also claim that if the composite is highly cross-linked by high-molecular weight polymer molecules, the whitener may require more time to diffuse through the material.

In our study we focused on a single, extensively studied and well-known nanofill universal composite, which may produce unique interactions with water, the staining solution and specially with the tooth whitener. Therefore, our results should be regarded with caution, not extrapolated to other tooth-coloring materials. This study also attempted to simulate clinical whitening by a home-whitening protocol based on $10 \%$ carbamide peroxide and revealed that a $3.35 \%$ hydrogen peroxide release ${ }^{1}$ during a 4 -hour/day period was sufficient to recover color change of the composite following staining with coffee. Based on that, one could infer that a clinical in-office whitening protocol based on $35 \%$ hydrogen peroxide would easily reach the same results.

The home whitening protocol based on application of $10 \%$ carbamide peroxide did not alter significantly the color of the studied nanocomposite, except if it was stained previously with extrinsic pigments, confirming the study hypothesis. One-week whitening was sufficient to recover color change to an acceptable level.

\section{References}

1. Kwon SR, Wertz PW. Review of the mechanism of tooth whitening. J Esthet Restor Dent. 2015 Sep-Oct;27(5):240-57. doi: 10.1111/jerd.12152.
2. Silva MFA, Davies RM, Stewart B, DeVizio W, Tonholo J, da Silva Júnior JG, et al. Effect of whitening gels on the surface roughness of restorative materials in situ. Dent Mater. 2006 Oct;22(1):919-24.

3. Li Q, Yu H, Wang Y. Colour and surface analysis of carbamide peroxide bleaching effects on the dental restorative materials in situ. J Dent. 2009 May;37(5):348-56. doi: 10.1016/j.jdent.2009.01.003.

4. Barutcigil Ç, Yildiz M. Intrinsic and extrinsic discoloration of dimethacrylate and silorane based composites. J Dent. 2012 Jul;40 Suppl 1:e57-63. doi: 10.1016/j.jdent.2011.12.017.

5. Kaizer Mda R, Diesel PG, Mallmann A, Jacques LB. Ageing of siloranebased and methacrylate-based composite resins: effects on translucency. J Dent. 2012 Jul;40 Suppl 1:e64-71. doi: 10.1016/j.jdent.2012.04.014.

6. Biazuz J, Zardo P, Rodrigues-Junior SA. Water sorption, solubility and surface roughness of resin surface sealants. Braz J Oral Sci. 2015 Jan-Mar; 14(1):27-30. doi: 10.1590/1677-3225v14n1a06.

7. Abu-Bakr N, Han L, Okamoto A, Iwaku M. Color stability of compomer after immersion in various media. J Esthet Dent. 2000; 12(5):258-63.

8. Fontes ST, Fernández MR, Moura CM, Meireles SS. Color stability of a nanofill composite: effect of different immersion media. J Appl Oral Sci. 2009 Sep-Oct;17(5):388-91.

9. Villalta P, Lu H, Okte Z, Garcia-Godoy F, Powers JM. Effects of staining and bleaching on color change of dental composite resins. J Prosthet Dent. 2006 Feb;95(2):137-42.

10. Bandeira de Andrade IG, Basting RT, Rodrigues JA, do Amaral FB, Turssi $\mathrm{CP}$, França FG. Microhardness and color monitoring of nanofilled resin composite after bleaching and staining. Eur J Dent. 2014 Apr;8(2):160-5. doi: 10.4103/1305-7456.130586.

11. Rodrigues SA Jr, Ferracane JL, Della Bona A. Influence of surface treatments on the bond strength of repaired resin composite restorative materials. Dent Mater. Apr;25(4):442-51. doi: 10.1016/j.dental.2008.09.009.

12. Ferracane JL. Hygroscopic and hydrolytic effects in dental polymer networks. Dent Mater. 2006 Mar; 22(3):211-22.

13. Anfe TE, Agra CM, Vieira GF. Evaluation of the possibility of removing staining by repolishing composite resins submitted to artificial aging. J Esthet Restor Dent. 2011 Aug;23(4):260-7. doi: 10.1111/j.1708-8240.2011.00435.x.

14. Mendes APKF, Barceleiro MO, Reis RSA, Bonato LL, Dias KRHC. Changes in surface roughness and color stability of two composites caused by different bleaching agents. Braz Dent J. 2012; 23(6):659-66.

15. Bagheri R, Tyas MJ, Burrow MF. Subsurface degradation of resin-based composites. Dent Mater. 2007 Aug; 23(8):944-51.

16. Drubi-Filho B, Garcia LFR, Cruvinel DR, Sousa ABS, Pires-de-Souza FCP. Color stability of modern composites subjected to different periods of accelerated artificial aging. Braz Dent J. 2012; 23(5):575-80.

17. Rodrigues SA Jr, Scherrer SS, Ferracane JL, Della Bona A. Microstructural characterization and fracture behavior of a microhybrid and a nanofill composite. Dent Mater. 2008 Sep;24(9):1281-8. doi: 10.1016/j. dental.2008.02.006.

18. Garoushi S, Lassila L, Hatem M, Shembesh M, Baady L, Salim Z, et al. Influence of staining solutions and whitening procedures on discoloration of hybrid composite resins. Acta Odontol Scand. 2013 Jan;71(1):144-50. doi: 10.3109/00016357.2011.654253.

19. Bagheri R, Burrow MF, Tyas M. Influence of food-simulating solutions and surface finish on susceptibility to staining of aesthetic restorative materials. J Dent. 2005 May; 33(5):389-98.

20. Soares DG, Basso FG, Pontes ECV, Gacia LFR, Hebling J, Souza Costa CA. Effective tooth-bleaching protocols capable of reducing $\mathrm{H} 2 \mathrm{O} 2$ diffusion through enamel and dentin. J Dent. 2014 Mar;42(3):351-8. doi: 10.1016/j. jdent.2013.09.001.

21. Durner J, Obermaier J, llie N. Investigation of different bleaching conditions on the amount of elutable substances from nano-hybrid composites. Dent Mater. 2014 Feb;30(2):192-9. doi: 10.1016/j.dental.2013.11.003.

22. El-Murr J, Ruel D, St-Georges AJ. Effects of external bleaching on restorative materials: a review. J Can Dent Assoc. 2011; 71:b59. 